\title{
Regenerated thermosetting styrene-co-acrylonitrile sandwich composite panels reinforced by jute fibre: structures and properties
}

\author{
JINGLONG LI I,2, QIN PENG ${ }^{1,2}$, ANRONG ZENG ${ }^{1,2}$, JUNLIN LI ${ }^{1,2}$, XIAOLE WU ${ }^{1,2}$ and \\ XIAOFEI LIU ${ }^{1,2, *}$ \\ ${ }^{1}$ Department of Polymer Materials Science and Engineering, College of Materials Science and Engineering, \\ Tianjin University, Weijin Road 92, Nankai District, Tianjin 300072, PR China \\ ${ }^{2}$ Tianjin Key Laboratory of Composite and Functional Materials, Tianjin University, Tianjin 300072, PR China
}

MS received 13 January 2015; accepted 24 August 2015

\begin{abstract}
Jute fibres-reinforced sandwich regenerated composite panels were fabricated using industrial waste thermosetting styrene-co-acrylonitrile (SAN) foam scraps via compression moulding for the purpose of recycling waste SAN foam and obtaining high physical performance. The jute fibres were, respectively, treated by heat, sodium hydroxide $(\mathrm{NaOH})$ solution $(5.0 \mathrm{wt} \%)$, and $\mathrm{N}, \mathrm{N}$-dimethylacetamide (DMAc) in order to improve the mechanical properties of the composites. The structures and mechanical properties of the composites were studied. The SAN matrix got compact and some crystalline region formed in SAN matrix via compression moulding. The composite reinforced by DMAc-treated jute fibres performed optimum mechanical properties among the regenerated panels whose impact strength, flexural strength, and compressive strength were $19.9 \mathrm{~kJ} \mathrm{~m}^{-2}, 41.7 \mathrm{MPa}$, and $61.0 \mathrm{MPa}$, respectively. Good interfacial bonding between DMAc-treated fibres and SAN matrix was verified by peel test and exhibited in SEM photographs. Besides, the water absorption of DMAc-treated fibres composite was lower than other SAN/jute fibre-reinforced sandwich composite panels.
\end{abstract}

Keywords. Jute fibre composite; thermosetting SAN; regeneration; fibre surface treatment; mechanical property; water absorption.

\section{Introduction}

With the increasing use of thermosetting materials for industrial and other applications in recent decades, more and more problems of recycling have been aroused by these materials. The most important problem is the disposal of the waste thermosetting material scraps. Many research groups have studied the recycling of thermosetting material scraps. For example, Quadrini et al [1] made a successful attempt on recycling of thermoset polyurethane foams scraps to prepare regenerated panel. The thermosetting materials, such as styrene-coacrylonitrile (SAN) foam materials, are difficult to recycle because of their indissolvable and refractory cross-linked structure. For this reason, these thermosetting material scraps were usually buried or burned in the past decades.

Generally, three methods are used to recycle thermosetting material, including chemical recycling, physical recycling, and energy recycling [2]. Physical recycling is environmentally friendly and efficient. Moreover, compression moulding is a typical physical recycling method to recycle thermosetting material scraps [3], and its recycle rate could be up to $100 \%$ [4]. Compression moulding is used for processing thermosetting material scraps at the suitable temperatures and pressures without additional binders.

\footnotetext{
*Author for correspondence (liuxf315@aliyun.com)
}

However, recycled materials through compression moulding did not have satisfactory mechanical properties [5] such as high impact strength, which limited applications in our daily life. In order to solve the problem, fibres were often introduced to reinforce the recycled materials and to reduce the cost of finished products in plastic industry [6]. Jute fibre has wide applications due to its workable specific modulus, renewable nature, low temperature of processability, corrosion resistance, low cost, non-abrasive nature, and the lowest specific gravity $[7,8]$. For these reasons, high filling amount is allowed which leads to significant increment of properties and decline in the cost of production [9].

The surface treatment of jute fibre is important [10,11], since the properties of composites depend on a system heterogeneity which leads to processing limitations, wettability, and chemical compatibility between hydrophilic fibres and hydrophobic polymer matrices [12]. Strong adhesion is needed for effective transfer of stress from matrix to fibres in composites materials $[12,13]$. Hence the treatment of jute fibres' surface is necessary for improving the surface properties and reducing the water absorption [14,15]. Alkalization is prevailing process for the surface treatment of jute fibres because of its low cost, high efficiency, and convenience [16]. Razera and Frollini [17] researched the phenolic-based sandwich composites with different treated jute fibres and found that the composite with $5.0 \mathrm{wt} \% \mathrm{NaOH}$-treated fibre reached the optimum impact strength. Sinha and Rout [18] reported 
that the flexural strength of unsaturated polyester composite with 4 h $5 \% \mathrm{NaOH}$-treated jute fibres was dramatically improved. Vilay et al [19] found that the tensile strength of unsaturated polyester composites was improved significantly when the natural fibre was treated with $1 \%$ concentration $\mathrm{NaOH}$. Perhaps different concentrations to treat jute fibres are adopted in different composite systems, but the concentration of $\mathrm{NaOH}$ was merely above $10 \%$ because natural fibres become weaker and get damaged after high concentration of $\mathrm{NaOH}$ treatment [20]. Besides, the acetylation is also a common surface treatment of fibre. Zou et al [21] found that the acetylation treatment was a desirable surface treatment method owing to the maximum tensile strength and water resistance. Different thermosetting composites reinforced by treated jute fibres have been reported [22], but few studies on the treated jute fibre-reinforced thermosetting SAN scraps have been reported so far.

In this study, novel jute fibre-reinforced sandwich composites based on the waste thermosetting SAN foam scraps (SAN/JF) were fabricated via compression moulding. The jute fibres modified by different surface treatments were used to reinforce the regenerated composite panel. The relationships between mechanical properties (impact strength, compressive strength and flexural strength) and structures of the regenerated composite panels were investigated.

\section{Experimental}

\subsection{Materials}

Industrial thermosetting SAN foam scraps without further purification were provided by Gurit Company. The average particle size of SAN foam scraps was $300-1000 \mu \mathrm{m}$. The content of cyano-group in SAN is about $30 \%$ and that of phenyl group is about $60 \%$. Meanwhile, the content of other additives is about $10 \%$ such as flame retardant or plasticizer.

Jute fibres supplied by Oriental Jute Fiber Products Limited Company (China) were used as the reinforcement. The fibres were washed and dried in air for $72 \mathrm{~h}$ at room temperature, and then were cut into $80 \mathrm{~mm}$ length. The properties of jute fibre were shown in table 1 .

\subsection{Surface treatments}

The untreated fibres (JF-U) were used as control group without any treatment. To improve the interfacial bonding of SAN

Table 1. Properties of jute fibre. ${ }^{\mathrm{a}}$

\begin{tabular}{lc}
\hline Properties & Jute fibre \\
\hline Density $\left(\mathrm{g} \mathrm{cm}^{-3}\right)$ & $1.25( \pm 0.02)$ \\
Cellulose content $(\%)$ & $57( \pm 3)$ \\
Hemicelluloses content $(\%)$ & $26( \pm 2)$ \\
Lignin content $(\%)$ & $15( \pm 2)$ \\
Diameter $(\mu \mathrm{m})$ & $125( \pm 15)$ \\
\hline
\end{tabular}

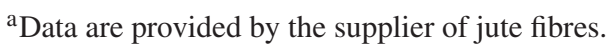

regenerated panels, three treatments (heat treatment, $\mathrm{NaOH}$ treatment, and DMAc treatment) were introduced to refine the surface of jute fibres, and the corresponding treated fibres were, respectively, denoted as JF-H, JF-A and JF-D.

(1) Heat treatment: The fibres were heated at $150^{\circ} \mathrm{C}$ in the oven for $60 \mathrm{~min}$.

(2) $\mathrm{NaOH}$ treatment: The fibres were immersed in $5.0 \mathrm{wt} \%$ $\mathrm{NaOH}$ aqueous solutions at $60^{\circ} \mathrm{C}$ for $60 \mathrm{~min}$. Then, the fibres were rinsed with deionized water and dilute hydrochloric acid until they became neutral and were dried at room temperature in air circulation to constant weight.

(3) DMAc treatment: The fibres were immersed in DMAc by rapid stirring at room temperature for $5 \mathrm{~min}$ in fume hood. Then, DMAc was squeezed out from the fibres at room temperature.

\subsection{Processing}

The composites consist of a layer of jute fibres sandwiched between two layers of thermosetting SAN. The jute fibres were paved between two equal layers of SAN scraps, and the composites were prepared by compression moulding. The moulding temperature was set at $195^{\circ} \mathrm{C} / 185^{\circ} \mathrm{C}$ (the temperatures of upper surface and bottom surface). Compression moulding was carried out at a constant pressure of $15 \mathrm{MPa}$. The moulding time was set in $15 \mathrm{~min}$. The contents of jute fibre were $0,2.5,5,7.5,10 \mathrm{wt} \%$ of SAN scraps in each case for comparison. The thickness of regenerated composite panel is $15 \mathrm{~mm}$. After demoulded, the regenerated panels were cold pressed for $10 \mathrm{~min}$ at room temperature.

\subsection{Characterizations}

2.4a Fourier transform infrared (FT-IR) spectroscopy: The chemical structures of SAN scraps and neat SAN regenerated panel were analysed by Fourier transform infrared (FT-IR) spectrometer (Bruker VECTOR22, Germany). The powders of thermosetting SAN scraps and specimen are ground with $\mathrm{KBr}$ and tableted.

2.4b X-ray diffraction (XRD) test: SAN scraps and specimen of SAN regenerated panel (10 $\mathrm{mm}$ long, $15 \mathrm{~mm}$ thick) were tested on X-ray diffractometer (Rigaku/DMAX, Japan).

2.4c Thermal stability: Thermogravimetric analysis (TGA) was used to determine the thermal stabilities of SAN scraps and SAN regenerated panel under elevated temperatures using Thermogravimetric Analyzer (Rigaku Thermo-flex, Japan). The specimens were heated from 40 to $800^{\circ} \mathrm{C}$ at a

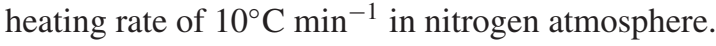

2.4d Differential scanning calorimetry (DSC) analysis: DSC was used to determine the heat behaviours of the SAN 
foam scraps and neat SAN regenerated panel under elevated temperatures using Differential Scanning Calorimeter (Rigaku Thermo-flex, Japan) in nitrogen atmosphere. The specimens were heated from 40 to $800^{\circ} \mathrm{C}$ at a heating rate of $10^{\circ} \mathrm{C} \mathrm{min}-1$ in nitrogen atmosphere.

2.4e Morphology studies: The surfaces of treated jute fibres and impact fracture surfaces of the composites were observed using a scanning electron microscope (SEM) (Philips XL 30, Netherlands). In order to reduce the extent of sample arcing, the fracture surfaces of the composite samples were coated with gold by means of a plasma sputtering apparatus prior to SEM observation.

\subsection{Physical properties}

2.5a Density: The specimens of the panels were cut into the cuboid of $30 \mathrm{~mm} \times 15 \mathrm{~mm} \times 15 \mathrm{~mm}$. The mass of cuboid test piece was weighed on electronic balance (accurate to $0.01 \mathrm{~g})$ at $20 \pm 2{ }^{\circ} \mathrm{C}$ and relative humidity of $(60 \pm 5) \%$. The thickness, length, and breadth of the test pieces were measured by vernier caliper (accurate to $0.01 \mathrm{~mm}$ ). The density of test piece was calculated by

$$
\rho=\frac{1000 \times m}{a \times b \times h},
$$

where $\rho$ is the density of regenerated panel $\left(\mathrm{g} \mathrm{cm}^{-3}\right), m$ the mass of test piece $(\mathrm{g}), a$ the length of test piece $(\mathrm{mm}), b$ the breadth of test piece $(\mathrm{mm})$, and $h$ the thickness of test piece $(\mathrm{mm})$.

2.5b Impact test: The impact strengths of regenerated composite panels were measured on a Charpy impact tester (XJJD-5 Chengde Jinjian Testing Instrument Limited Company, China) operated with a pendulum length of $225 \mathrm{~mm}$ and a pendulum of $40 \mathrm{~J}$ according to DIN EN ISO 179. The specimens of sandwich composites were cut into strips with dimensions of $80 \mathrm{~mm}$ long $\times 15 \mathrm{~mm}$ wide $\times 15 \mathrm{~mm}$ thick. At least three specimens of each composite were tested and the results were averaged.

2.5c Flexural test: The flexural strengths of regenerated composite panels were measured using a three-point bending test according to DIN EN ISO 178 by universal testing machine (M350-20KN Rochdate, UK). The flexural tests were done at a crosshead speed of $1.5 \mathrm{~mm} \mathrm{~min}^{-1}$. The flexural test specimens of sandwich composites were cut into strips with dimensions of $80 \mathrm{~mm}$ long $\times 15 \mathrm{~mm}$ wide $\times 15 \mathrm{~mm}$ thick. At least three specimens were measured for each composite and the results were averaged.

2.5d Compressive test: The compressive strengths of regenerated composite panels were measured by Universal Mechanical Testing Machine (M350-20KN Rochdate, UK) according to DIN EN ISO 604. The compressive test specimens of the composites were cut into strips with dimensions of $80 \mathrm{~mm}$ long $\times 15 \mathrm{~mm}$ wide $\times 15 \mathrm{~mm}$ thick. At least three specimens were measured for each composite and the results were averaged.

2.5e Peel strength: To study the combination between the fibres and SAN matrix, the test of peel strength was introduced. The test pieces of different composites were cut into $25 \mathrm{~mm}$ wide according to GB/T 7122-1996. The upper SAN layers of the composites were removed in order to expose the fibres and peel the fibres from the SAN matrices in peel test. The peel test was performed on $90^{\circ}$ peel strength tester (HD-220, Dongguan, China). The loading speed was $100 \mathrm{~mm} \mathrm{~min}^{-1}$. At least three specimens were measured for each composite and the results were averaged.

$2.5 \mathrm{f}$ Water absorption of regenerated sandwich composite panel: The specimens of the composites were cut into strips with dimensions of $30 \mathrm{~mm}$ long $\times 15 \mathrm{~mm}$ wide $\times$ $15 \mathrm{~mm}$ thick and were oven dried at $50^{\circ} \mathrm{C}$ for $24 \mathrm{~h}$ to a constant weight $\left(M_{0}\right)$. Then the specimens were immersed in distilled water and periodically taken out of the water. The surfaces of specimens after immersion in water were dried with absorbent paper and the specimens were weighed using an analytical balance with $0.1 \mathrm{mg}$ precision $\left(M_{t}\right)$. The water absorption at time $t\left(W_{t}\right)$ was calculated by using equation (2). The specimens were immersed until saturated. At least three specimens of each composite were tested and the results were averaged

$$
W_{t}(\%)=\frac{M_{t}-M_{0}}{M_{0}} \times 100,
$$

where $M_{0}$ is the initial weight of dried specimens $(\mathrm{g}), M_{t}$ the weight after immersing in water $(\mathrm{g})$, and $W_{t}$ the water absorption $(\mathrm{g})$.

\section{Results and discussion}

\subsection{Chemical structure of SAN foam scraps and regenerated composite panel}

To determine the change of SAN before and after compression moulding, the characterizations were used to analyse the chemical structures of SAN scraps and neat SAN panel (regarding as SAN matrix in composite).

3.1a FT-IR analysis: The FT-IR spectra of SAN scraps and regenerated panel are shown in figure 1 . The results were analysed as following $\left(\mathrm{KBr}\right.$, tableting, $\left.v_{\max } / \mathrm{cm}^{-1}\right): 3030$ $(=\mathrm{C}-\mathrm{H}) ; 2250(-\mathrm{C} \equiv \mathrm{N}) ; 761$ and 703 (mono-substitution benzene ring); 1600, 1548, and 1503 (out-of-plane vibration of benzene ring). Through comparing, these characteristic absorption peaks of the two curves are basically the same. 


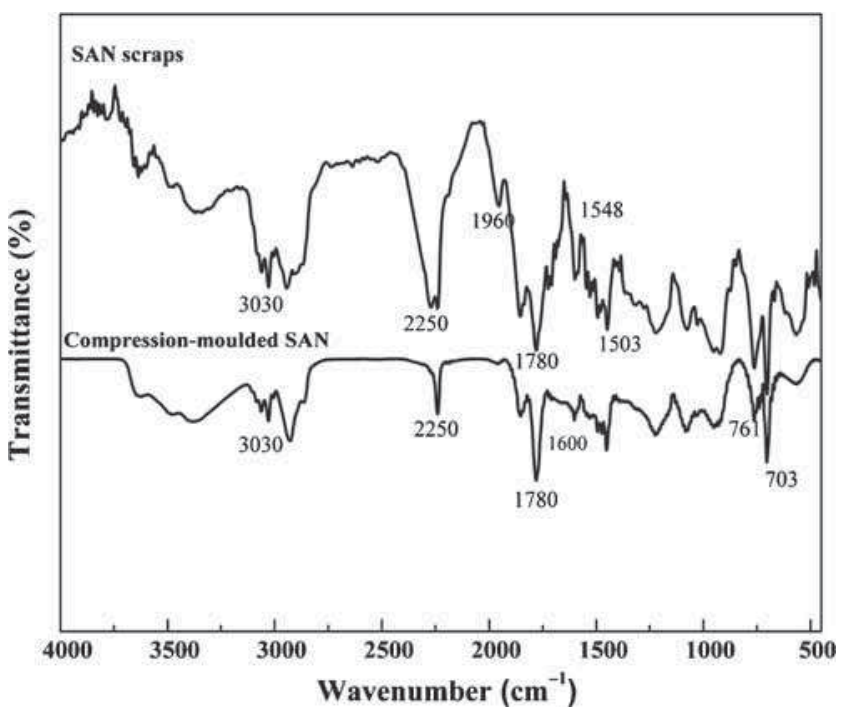

Figure 1. FT-IR spectra of the SAN scraps and neat SAN regenerated panel.

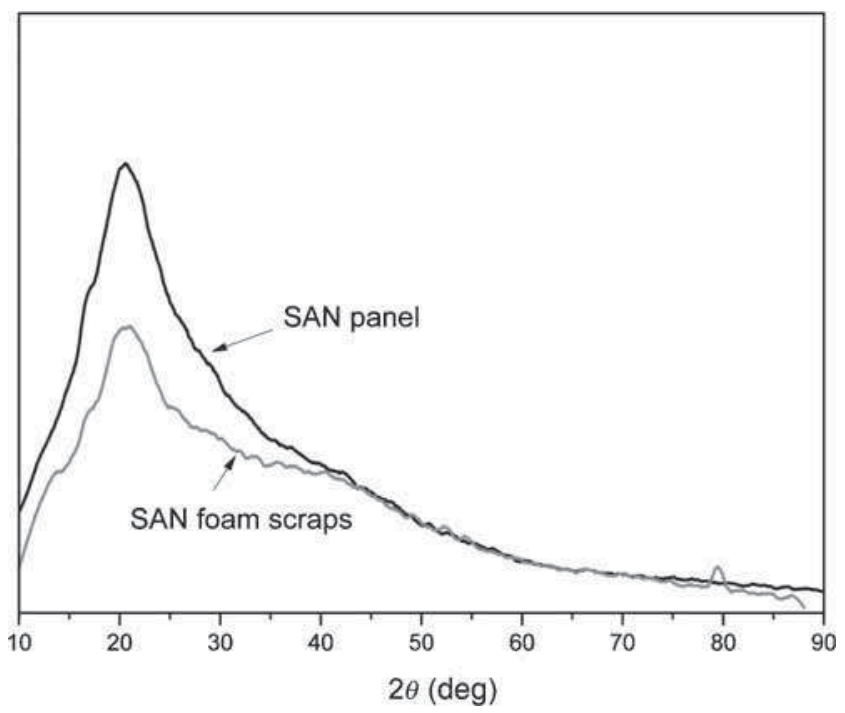

Figure 2. X-ray diffraction patterns of the SAN scraps and neat SAN regenerated panel.

That means the main functional groups of SAN does not obviously change after compression moulding. Meanwhile, some absorption peaks decrease such as $1960 \mathrm{~cm}^{-1}(\mathrm{C}=\mathrm{O})$, which means some additives or impurities decomposed or volatilized via compression moulding.

3.1b XRD analysis: Figure 2 shows the XRD patterns of the SAN scraps and SAN regenerated panel. There are both peaks at about $2 \theta=20^{\circ}$ in the two patterns, and the main difference is the intensity of the two diffraction peaks. It can be inferred that some linear chain segments in the uncrosslinked phase of SAN matrix have oriented under the highpressure compression and formed some crystalline regions in the SAN matrix, which is similar to the model Fukahori [23] proposed about the self-reinforcement of cross-linked natural rubber. Because the raw material is a kind of thermoset foam, there are considerable closed pores in it which abandoned the contact of a part of the molecular chains. Thanks to the hot compression moulding, more molecular chains contacts compactly and arranged orderly by high pressure and intermolecular force.

3.1c Thermal analysis: In the curves of TGA (figure 3), slight weight loss are observed when temperature is below $200^{\circ} \mathrm{C}$, which means SAN foam is stable under the compression moulding condition besides the volatilization of the additives. The SAN regenerated panel is more stable above $300^{\circ} \mathrm{C}$ since the mass is higher than SAN scraps, which may means the structure of the SAN matrix have changed after compression moulding. However, the DSC curves of SAN scraps and regenerated panel in figure 4 are quite different. When the temperature rises to about $150^{\circ} \mathrm{C}$, an endothermic

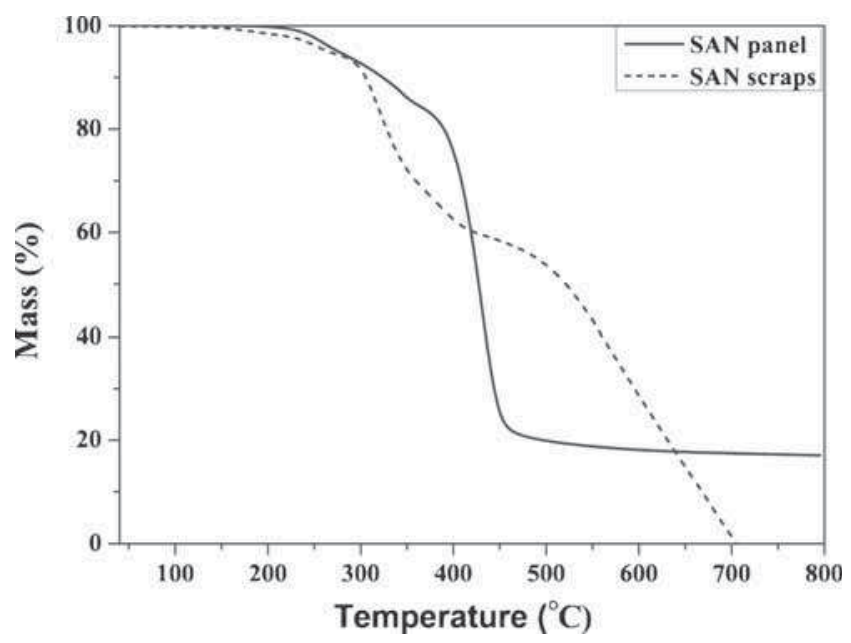

Figure 3. TG curves of the raw SAN scraps and neat SAN regenerated panel.

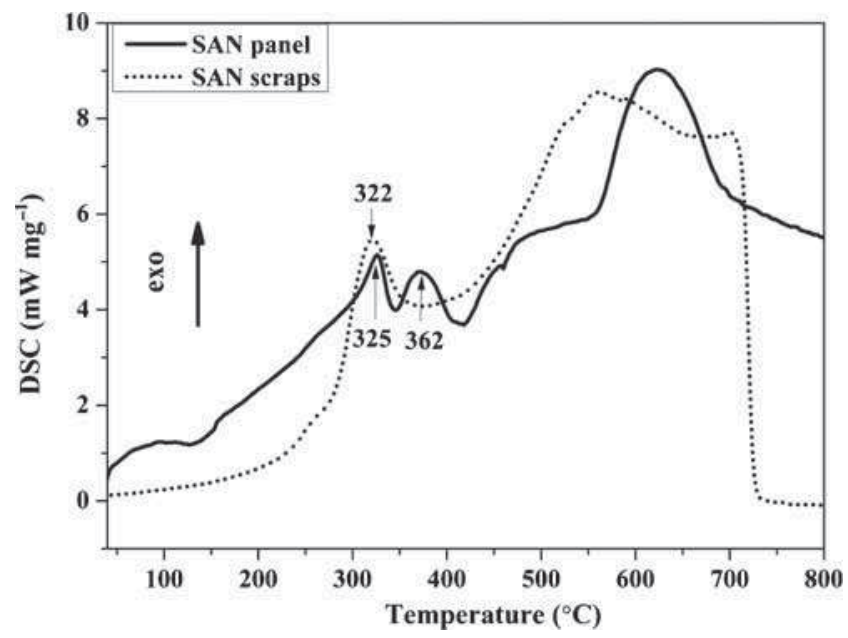

Figure 4. DSC curves of the raw SAN scraps and neat SAN regenerated panel. 
peak appears in the curve of SAN panel, which means some semi-crystalline structure in the SAN matrix was plasticized slightly. Besides, there are both split exothermic peaks around $320^{\circ} \mathrm{C}$ in the two curves, which means some crosslink structure formed. After $325^{\circ} \mathrm{C}$, SAN started to decompose. A new exothermic peak can be found at $362^{\circ} \mathrm{C}$ in the curve of SAN regenerated panel, which means new crosslink structure appeared at $362^{\circ} \mathrm{C}$. Since the compact structure of the regenerated panel (see in table 2), there are more contacts between molecular chains in the regenerated panel which contributes to the new crosslink structures. According to the thermal analysis, it can be inferred that compression

Table 2. Densities of SAN foam, SAN regenerated panel and SAN/JF composites.

\begin{tabular}{lc}
\hline Panel & $\rho\left(\mathrm{g} \mathrm{cm}^{-3}\right)$ \\
\hline SAN foam & $0.07-0.08^{\mathrm{a}}$ \\
SAN regenerated panel & $0.98 \pm 0.02$ \\
SAN/JF-U panel $^{\mathrm{b}}$ & $0.99 \pm 0.01$ \\
SAN/JF-H panel $^{\mathrm{b}}$ & $1.02 \pm 0.02$ \\
SAN/JF-A panel $^{\mathrm{b}}$ & $1.02 \pm 0.01$ \\
SAN/JF-D panel $^{\mathrm{b}}$ & $1.04 \pm 0.01$ \\
\hline
\end{tabular}

${ }^{\mathrm{a}}$ Data are provided by the supplier of SAN foam.

bute fibre wt $\%: 5.0 \%$.
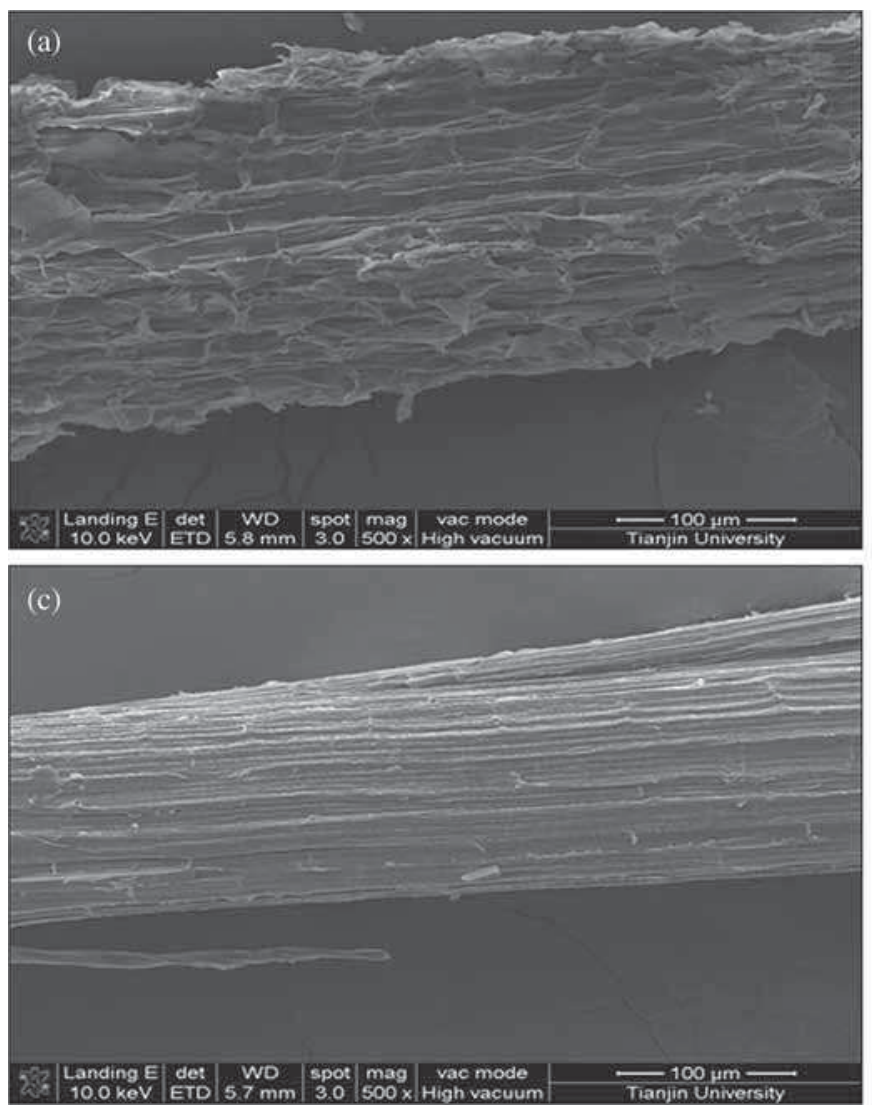

moulding is feasible to recycle the waste thermosetting SAN foam scraps at the processing temperature.

It can be concluded from the characterizations that the chemical structure of thermosetting SAN has been changed via compression moulding, which infers the chemical structure of SAN matrix can help to provide physical performance in the regenerated composite panels, but the SAN matrix possess rigidness. Jute fibres are introduced to improve the mechanical properties of regenerated composite panels, especially toughness.

\subsection{The surface treatment of jute fibre}

The mechanical properties of composites depend on the adhesion between matrix polymer and fibres, and the interphase properties [12]. Hydroxyl groups on the natural fibres lead to high water absorption, resulting in good wettability and weak interfacial bonding between fibres and hydrophobic matrices [13]. Meanwhile, some substances (lignin, wax, oils, etc.) on the surface of fibres also affect the interaction between fibres and matrix (figure 5a). In order to improve the mechanical properties of regenerated sandwich composite panel, it is necessary to improve the interaction between jute fibres and SAN matrix. Different methods (heat, alkali and DMAc treatments) were introduced to modify the surface of jute fibres in order to improve the adhesion of jute fibres and
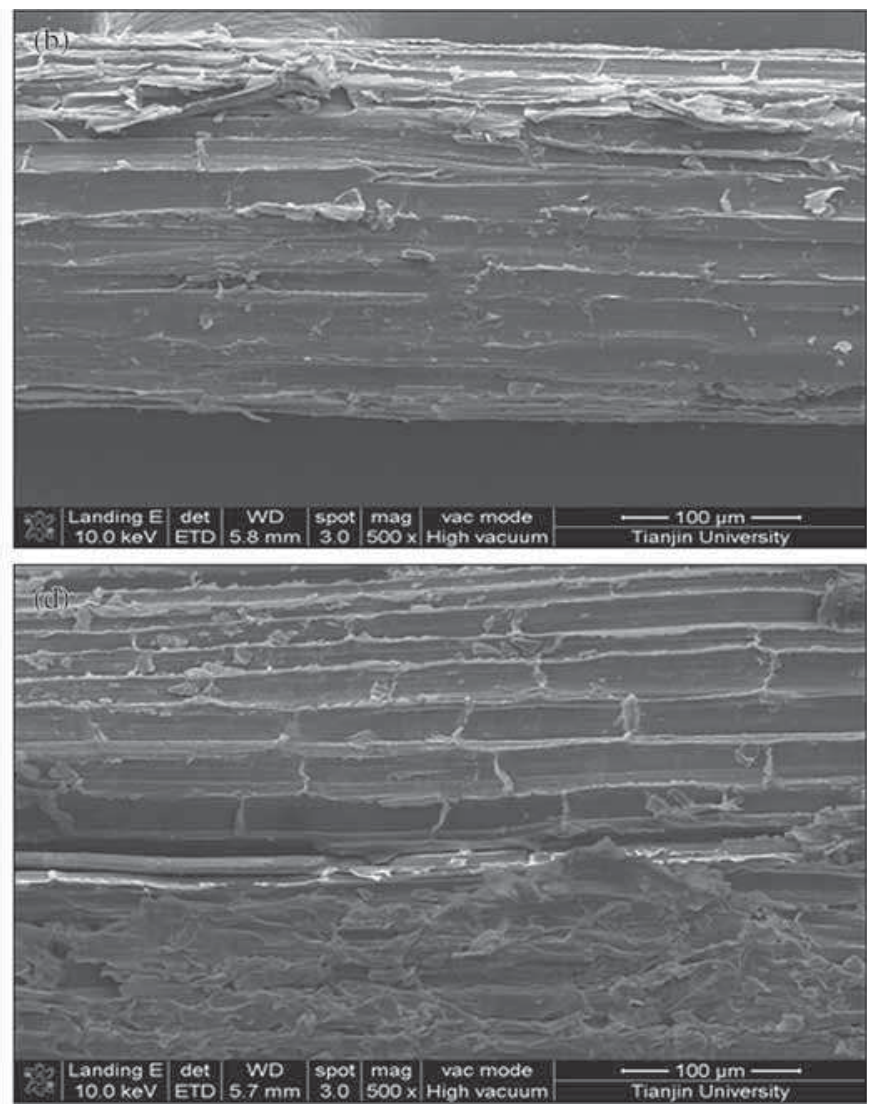

Figure 5. SEM micrographs of the jute fibre surface: (a) JF-U $(500 \times$ magnification), (b) JF-H $(500 \times$ magnification), (c) JF-A $(500 \times$ magnification) and (d) JF-D (500× magnification). 
SAN scraps in interphase region, which improved the mechanical properties of regenerated sandwich composite panel. Besides, the surface modification of jute fibre also aims to decrease moisture absorption because of the reduction of hemicellulose [24] or some other hydrophilic substances.

The surface morphologies of jute fibre with different treatments were analysed by SEM. Figure 5a reveals the surface of untreated fibres is rough, because of much pectin or lignin existing on the fibre surface. The substances may reduce the contact area between fibres and SAN scraps, which leads to reduction of the adhesion capacity. Figure $5 b(\mathrm{JF}-\mathrm{H}), 5 \mathrm{c}$ (JF-A), and 5d (JF-D) illustrates that different treatments can remove the impurities on the fibre surface effectively, especially $\mathrm{NaOH}$ treatment. Water and other volatile substances was removed at $150^{\circ} \mathrm{C}$ with heat treatment; some substances possibly decomposed when fibres were heated at $150^{\circ} \mathrm{C}$ [11]. The surface of JF-A is relatively clean with small surface debris on it compared with JF-H and JF-D, and the fibre bundle was partly broken into filaments. This was because a certain amount of wax, oils, lignin and hemicellulose [17,20] were removed after $\mathrm{NaOH}$ treatment. For JF-D, there are many cavities on the surface since the partly removal of wax or other organic substances, which will help to the interfacial bonding between fibres and SAN particles.

\subsection{Properties of the regenerated sandwich composite panels}

3.3a The mechanical properties of regenerated sandwich composite panels: The mechanical properties of the SAN/JF composites are shown in table 3 . The mechanical properties of heat-treated fibre-reinforced composite (SAN/JF-H), $\mathrm{NaOH}$ treated fibre-reinforced composite (SAN/JF-A), and DMActreated fibre-reinforced composite (SAN/JF-D) are higher than untreated fibre composite (SAN/JF-U), which means surface treatments of jute fibre are important for the reinforcement.

Impact strength increases with the increase in content of untreated fibre (entries 1-5, table 3). Compared with the regenerated panel without jute fibres, the impact strength of $2.5 \mathrm{wt} \% \mathrm{SAN} / \mathrm{JF}-\mathrm{U}$ increases by $44.0 \%$, and that of the $5.0 \mathrm{wt} \% \mathrm{SAN} / \mathrm{JF}-\mathrm{U}$ increases by $104.4 \%$. The dramatically increment of impact strength reveals that the added fibres improve impact strength. However, the impact strength of $10.0 \mathrm{wt} \% \mathrm{SAN} / \mathrm{JF}-\mathrm{U}$ does not increase obviously compared with the load content $7.5 \mathrm{wt} \%$. Although the fibre content is growing, the impact strength seems not always rising. Entries 3 and 6-8 in table 3 indicate that the surface treatment is effective on increasing the impact property of the composites. Compared with SAN/JF-U (entry 3, table 3), the impact strength of different treated fibre-reinforced composite increases by $103.2 \%$ (SAN/JF-H), 37.0\% (SAN/JFA), and $116.3 \%$ (SAN/JF-D). It is possible that the adhesion between treated fibres and matrix has been improved to a certain extent via different treatment.

Nevertheless, flexural strength seems not to be improved with the increment of fibre content. The untreated fibres does not improve the flexural strength of sandwich composites panel, even decreases the flexural strength. The surface treatment of jute fibre has a positive effect on the flexural strength. SAN/JF-D panel still shows the better flexural property than others. Compared with SAN/JF-U (entry 3, table 3), the flexural strength of SAN/JF-H (entry 6, table 3 ) increases by $40.6 \%$, the SAN/JF-A (entry 7, table 3) increases by $28.7 \%$, and SAN/JF-D (entry 8, table 3 ) increases by $70.9 \%$.

The compressive strength of the neat regenerated panels is better than SAN/JF-U, indicating that the compressive strength decrease when JF-U added into the composites. The possible reason is bad combination between untreated fibres and SAN matrix (see figure 6a). The bad interfacial bonding between untreated fibres and SAN makes the interface of fibres as defects in the composites which decrease the compressive strength. SAN/JF-D still holds the best compressive property. Compared with SAN/JF-U (entry 3, table 3), the compressive strength of SAN/JF-H (entry 6, table 3) increase by $18.7 \%$, SAN/JF-A (entry 7 , table 3 ) increases by $8.3 \%$ and SAN/JF-D (entry 8 , table 3 ) increases by $41.2 \%$.

Through the comparison, an outstanding improvement of mechanical properties can be drawn much attention: the impact, flexural, and compressive strength of SAN/JF-D, respectively, increases by $342.2 \%, 69.5 \%, 22.2 \%$ compared with the neat SAN regenerated panel. The treated fibre composites perform better mechanical properties than untreated one. The introduction of treated fibres improves the toughness of the regenerated composite. In addition, the effect of the different treated fibres on the mechanical strength of

Table 3. Mechanical properties of the SAN/JF composite panels.

\begin{tabular}{lccccc}
\hline Entry & $\begin{array}{c}\text { Treatment } \\
\text { of fibre }\end{array}$ & $\begin{array}{c}\text { Content of } \\
\text { fibre (\%) }\end{array}$ & $\begin{array}{c}\text { Impact strength } \\
\left(\mathrm{kJ} \mathrm{m}^{2}\right)\end{array}$ & $\begin{array}{c}\text { Flexural } \\
\text { strength (MPa) }\end{array}$ & $\begin{array}{c}\text { Compressive } \\
\text { strength (MPa) }\end{array}$ \\
\hline 1 & - & 0 & $4.5 \pm 0.65$ & $24.6 \pm 2.15$ & $49.9 \pm 5.35$ \\
2 & Untreated & 2.5 & $6.5 \pm 0.91$ & $23.7 \pm 2.20$ & $45.9 \pm 4.97$ \\
3 & Untreated & 5.0 & $9.2 \pm 1.53$ & $24.4 \pm 2.05$ & $43.2 \pm 4.68$ \\
4 & Untreated & 7.5 & $11.5 \pm 1.60$ & $22.6 \pm 2.05$ & $36.6 \pm 5.03$ \\
5 & Untreated & 10.0 & $11.8 \pm 1.11$ & $25.3 \pm 1.63$ & $36.3 \pm 5.12$ \\
6 & Heat & 5.0 & $18.7 \pm 2.38$ & $34.3 \pm 2.63$ & $51.3 \pm 4.69$ \\
7 & NaOH & 5.0 & $12.6 \pm 2.07$ & $31.4 \pm 1.32$ & $46.8 \pm 4.35$ \\
8 & DMAc & 5.0 & $19.9 \pm 2.26$ & $41.7 \pm 2.47$ & $61.0 \pm 4.36$ \\
\hline
\end{tabular}



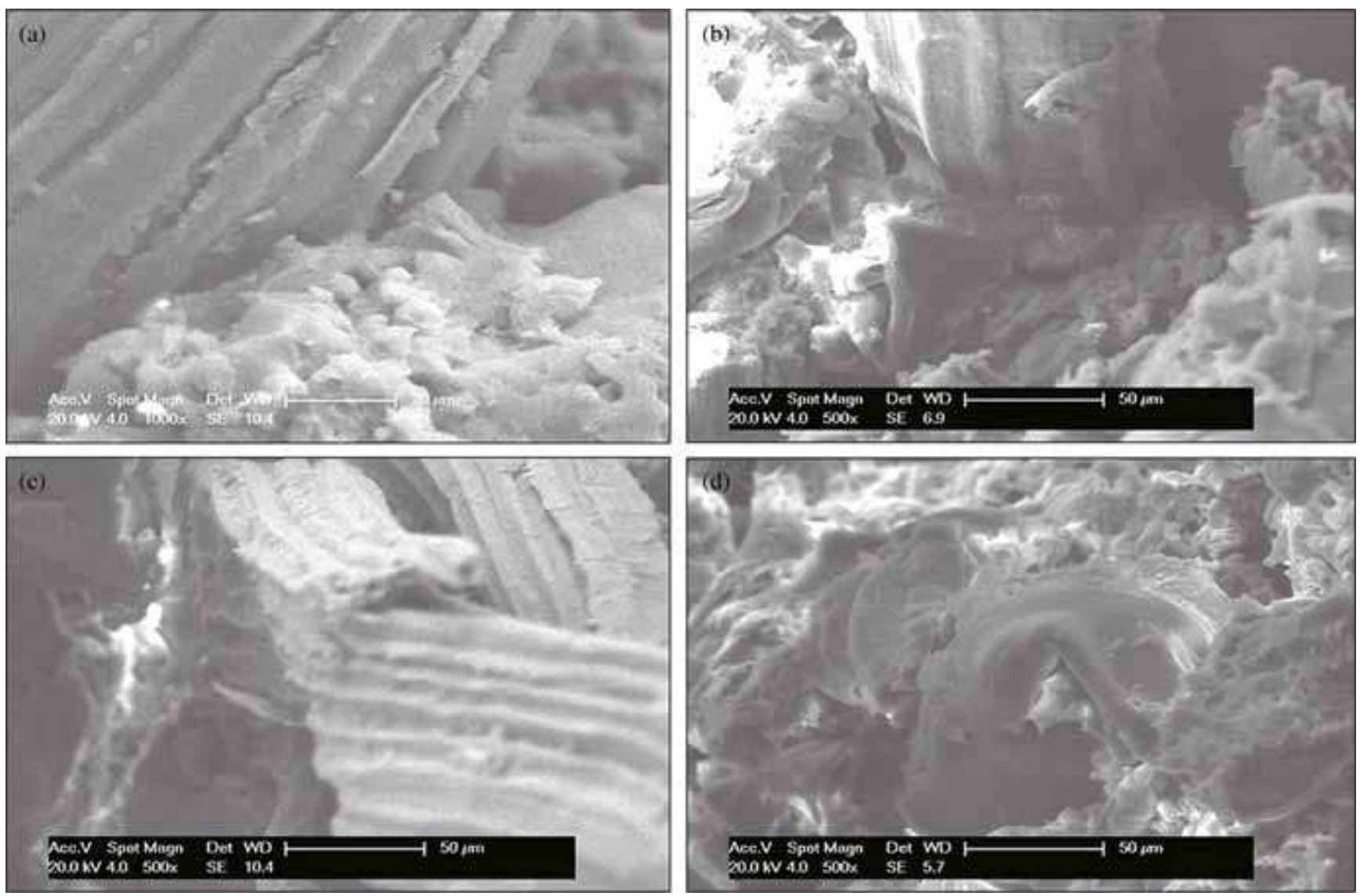

Figure 6. SEM micrographs of the regenerated composite panels fracture surfaces with different treated fibres $(500 \times$ magnification): (a) SAN/JF-U; (b) SAN/JF-H; (c) SAN/JF-A; and (d) SAN/JF-D.

Table 4. Effect of different treatments on the adhesion between JFs and SAN matrix.

\begin{tabular}{|c|c|c|c|}
\hline Fibres & JF-U & JF-H & JF-A \\
\hline
\end{tabular}

Peel strength $0.30 \pm 0.07 \quad 0.79 \pm 0.06 \quad 0.67 \pm 0.04 \quad 0.98 \pm 0.05$ $\left(\mathrm{N} \mathrm{mm}^{-1}\right)$

composites is evident. SAN/JF-D has better mechanical properties than SAN/JF-H and SAN/JF-A, and SAN/JFA has inferior mechanical properties among these SAN/JF composites, which means the mechanical properties are related with the treatment of fibres.

Different treatments of jute fibres result in the change of interfacial bonding, which can be indicated from the peel strength of the composites (see table 4). Good interfacial bonding which can be inferred from high peel strength affects the mechanical strength. The change of peel strength is similar to the mechanical strength of the composites from table 4. The peel strength of SAN/JF-U is lower than that of other composites, which means the treatment of jute fibres improves the adhesion between SAN and jute fibres effectively.

The peel strength of SAN/JF-H increases by $163.3 \%$ compared with SAN/JF-U. Water and other volatile substances are largely removed from jute fibres at $150^{\circ} \mathrm{C}$ via heat treatment, but some substances such as hemicellulose or lignin may not be largely removed. So the structure of JF-H is relative complete. $\mathrm{H}_{2} \mathrm{O}$ or other volatile substances in the jute fibres can affect the combination of jute fibres and SAN matrix. There is large gap and clear interface between untreated fibres and SAN matrix in figure 6a. Except the rough surface of JF-U, gap can be formed on the interface between JF-U and SAN matrix when volatile substances remaining in JF-U were heated to moulding temperature, which also resulted in bad combination between matrix and fibres. But heat treatment can avoid such case. Meanwhile, fewer impurities on the JF-H improve the combination between SAN and JF-H. Some shallow cavities left on the surface of JF-H can be filled with part of the SAN scraps and increases the interaction area between fibres and SAN scraps, resulting in improving the adhesion between fibres and SAN matrix in the processing. Figure $6 \mathrm{~b}$ shows the adhesion between JF-H and SAN matrix is much closer compared with figure 6a. Thus, the mechanical properties of SAN/JF-H are better than that of SAN/JF-U.

For JF-A, alkali reacts with hydroxyl groups of the fibres, and it brought fibre fibrillation [24] and collapse of the cellular structure owing to the removal of wax, hemicellulose, and lignin. Vilay et al [19] found that the fibrillation process 

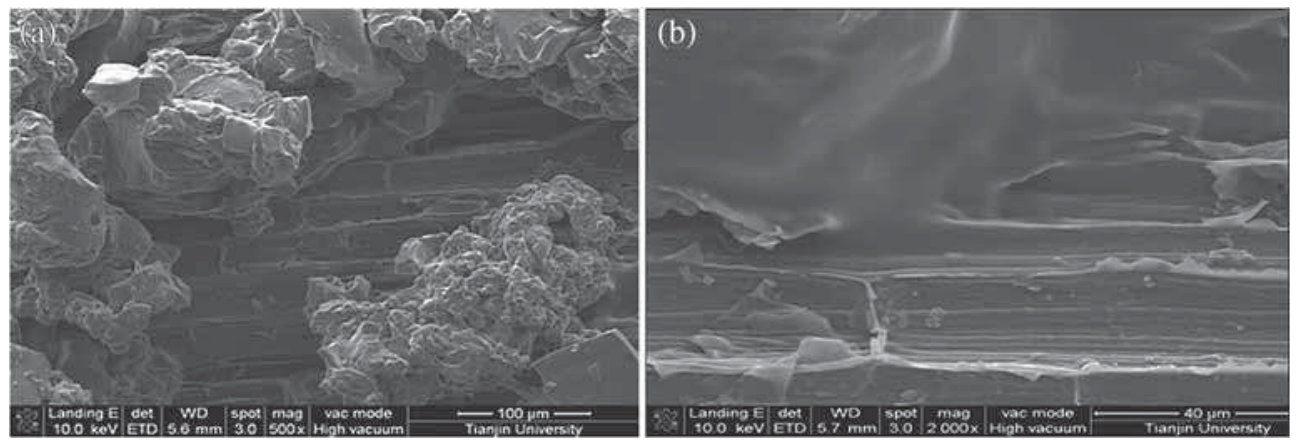

Figure 7. Interface between JF-D and SAN scraps in SEM micrographs: (a) 500 $\times$ magnification and (b) $2000 \times$ magnification.

caused by the treatment improves the fibre surface adhesion. For this reason, the peel strength increases by $123.3 \%$ compared with SAN/JF-U. Besides, the mechanical properties are higher than those of SAN/JF-U. Although fewer impurities on the surface of fibres, the clean surface of JF-A may not offer good mechanical interlocking on the interface yet (figure $6 \mathrm{c}$ ). Hence, the peel strength and mechanical properties of SAN/JF-A are lower than other treated fibre-reinforced composites.

However, the peel strength of SAN/JF-D increases by $46.3 \%$ compared with SAN/JF-A and reaches the maximum. DMAc can also partly remove the substances on the surface of jute fibres, which means DMAc has a moderated effect on the treatment of jute fibres compared with other two kinds of treatment. The remaining DMAc in the fibres may also help to swell the SAN scraps and part of the SAN scraps may enter the cavities on the fibres. In figure 7, the SAN particles swelled by remaining DMAc in fibres can adhere on the fibres well and exhibit fuzzy interface when SAN scraps were scattered on JF-D, which indicates good combination between JF-D and SAN. Through the hot compression moulding, SAN scraps were embed in the cavities on the fibres to reinforce the interfacial bonding. Thus, the interface between JF-D and SAN scraps is fuzzier than others (figure 6d). Good interfacial bonding between JF-D and SAN matrix will improve stress transfer from matrix to fibre, and the treated fibres are able to absorb energy effectively and dissipate energy effectively. For these reasons, the mechanical strength of SAN/JF-D is optimum, and the toughness of the regenerated panel improves.

3.3b Water absorption of regenerated sandwich composite panels: The water absorptions of the different regenerated sandwich composite panel are shown in figure 8. In all cases, the water absorption is steep at the beginning and becomes stable for some length of time where it approaches to equilibrium.

The water absorption of treated fibre composites is less than the untreated one as shown in figure 8. It also shows that water absorption of the composites reinforced by treated fibres is higher than that of neat SAN regenerated panel.

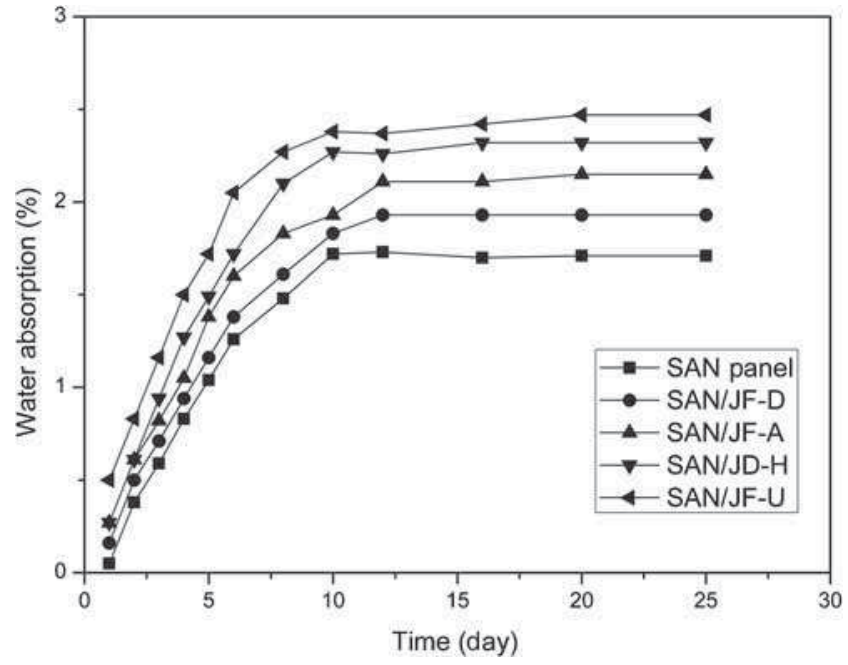

Figure 8. Water absorption of different SAN regenerated composite panels.

According to figure 8, the water absorption of SAN/JF-D is minimal among the three kinds of treated fibre composites, and that of SAN/JF-H is maximum because hemicellulose or other hydrophilic impurities was not largely removed. Compact structure prevents water entering into the composites after alkali and DMAc treatment regardless of the hydrophilicity after treatment. The result is similar to the conclusions proposed by Zou et al [21]. However, the water absorption of all composites is below $2.5 \%$, which indicates that the water absorption of SAN/JF composites is low.

\section{Conclusions}

A series of novel jute fibre-reinforced regenerated thermosetting SAN sandwich composite panels were successfully fabricated via compression moulding. The results of FT-IR, DSC, TG, and XRD revealed that some crystalline regions were generated in SAN matrix via compression moulding which offer good mechanical strength. Besides, the jute fibre offered toughness for the composite. The treated fibrereinforced composite panels performed better mechanical 
properties than the untreated fibre-reinforced composite. The mechanical strengths of DMAc-treated fibre-reinforced composite panel reached maximums: impact strength $19.9 \mathrm{~kJ} \mathrm{~m}^{-2}$, flexural strength 41.7 MPa, and compressive strength 61.0 $\mathrm{MPa}$. The peel strength and fracture morphology of the DMAc-treated fibre-reinforced SAN composites indicated the good fibre/matrix interfacial bonding between DMActreated fibres and SAN resulting in improving the mechanical properties of sandwich composite panels. The water absorption of DMAc-treated fibre composite was lower than other jute fibre/SAN composite panel because of the relative compact structure.

\section{Acknowledgement}

This work was supported by Tianjin Science and Technology Support Program (Grant number 10ZCKFSH02500).

\section{References}

[1] Quadrini F, Bellisario D and Santo L 2013 Polym. Eng. Sci. 531357

[2] Lee Y H, Kang B K, Kim H D, Yoo H J, Kim J S, Huh J H, Jung Y J and Lee D J 2009 Macromol. Res. 17616

[3] Hulme A J and Goodhead T C 2003 J. Mater. Process. Technol. 139322

[4] Zia K M, Bhatti H N and Ahmad Bhatti I 2007 React. Funct. Polym. 67675
[5] Satapathy S, Nando G B, Jose J and Nag A 2008 J. Reinf. Plast. Compos. 27967

[6] Reddy N and Yang Y 2005 Trends Biotechnol. 2322

[7] Singha A S and Thakur V K 2008 Bull. Mater. Sci. 31791

[8] Sever K 2009 J. Reinf. Plast. Compos. 291921

[9] Agarwal G, Agarwal K K and Roy S 2014 Front. Manuf. Eng. 21

[10] Parsania P and Patel V 2009 J. Reinf. Plast. Compos. 29725

[11] Thitithanasarn S, Yamada K, Ishiaku U S and Hamada H 2013 J. Appl. Polym. Sci. 1272952

[12] Goud G and Rao R N 2011 Bull. Mater. Sci. 341575

[13] Acha B A, Marcovich N E and Reboredo M M 2005 J. Appl. Polym. Sci. 98639

[14] Wang W M, Cai Z S and Yu J Y 2008 J. Eng. Fiber. Fabr. 31

[15] Doan T T L, Brodowsky H and Mäder E 2012 Compos. Sci. Technol. 721160

[16] Ray D, Sarkar B K, Rana A K and Bose N R 2001 Bull. Mater. Sci. 24129

[17] Razera I A T and Frollini E 2004 J. Appl. Polym. Sci. 911077

[18] Sinha E and Rout S K 2009 Bull. Mater. Sci. 3265

[19] Vilay V, Mariatti M, Mat Taib R and Todo M 2008 Compos. Sci. Technol. 68631

[20] Li X, Tabil L G and Panigrahi S 2007 J. Polym. Environ. 1525

[21] Zou H, Wang L, Gan H and Yi C 2012 Polym. Compos. 33 1659

[22] Thakur V K and Thakur M K 2014 Carbohydr. Polym. 109 102

[23] Fukahori Y 2010 Polymer 511621

[24] Shahzad A 2012 Polym. Compos. 331129 